PERO ŠKORPUT, M.Sc.

E-mail: pero.skorput@fpz.hr

SADKO MANDŽUKA, Ph.D.

E-mail: mandzukas@fpz.hr

NIKO JELUŠIĆ, Ph.D.

E-mail: jelusicn@fpz.hr

University of Zagreb,

Faculty of Transport and Traffic Sciences

Vukelićeva 4, HR-10000 Zagreb, Republic of Croatia
Inteligent Transport Systems (ITS)

Preliminary Communication

Accepted: Feb. 18, 2010

Approved: July 5, 2010

\title{
REAL-TIME DETECTION OF ROAD TRAFFIC INCIDENTS
}

\begin{abstract}
The paper analyses the real-time detection of incidents in road traffic. A general model is presented of an integral road traffic incident management system. The paper presents the major incident detection methods. The detection procedure on open highway sections has been dealt with in particular. Adequate mathematical model has been defined, as the base for the realisation of the estimators of the traffic flow condition variables. The proposed method is the Extended Kalman Filter. The final part of the paper deals with an example for the realisation of the Incident Management Decision Support System (IMDSS).
\end{abstract}

\section{KEY WORDS}

intelligent transport system, incident management system, traffic model in the status space, theory of estimation, extended Kalman filter, automatic incident detection, decision support system

\section{INTRODUCTION}

Road traffic incident management is a functional part of the holistic approach to solving traffic problems known under the term Intelligent Transportation System - ITS. The advanced development of communication and navigation technologies and their implementation in various phases of incident management can significantly reduce the consequences of incident event such as congestion, delay, pollution and especially dangerous secondary incidents [1]. The development of the incident management system is approached in a new and technologically innovative manner starting from adequate basis of the traffic flow theory, theory of dynamic system estimation, general theory of classification, as well as adequate ITS architectures, available technologies, etc. [2, 3, 4].

Real-time incident management in traffic comprises coordination activities undertaken by several actors in order to reduce the negative impact, i.e. recovery of the traffic flow to the conditions of normal flow. One of the basic problems in incident management is effective coordination of various organisations, i.e. services included in this process [5]. Besides, incident management comprises also legal regulations which require careful planning of all segments. The success of the incident management lies in careful development of clear (and efficient) instructions and procedures, which are acceptable and understandable for all the involved services, organisations and individuals. One of the important conditions to achieve this is high-quality communications among the participants, i.e. information transparency and real-time data flow. Absence of such an approach which combines cooperation, communication and training, represent one of the main reasons of inefficient incident management process, today $[5,6,7]$.

1. The critical point in the traffic incident management chain is the procedure of detecting the incident and the appropriate verification thereof. There are today different technologies used to achieve this. The basic classification of such systems is inttraffic incident detection systems in/on road structures (tunnels, bridges, viaducts, etc.),

2. traffic incident detection systems on open road sections.

The first group systems are based mainly on the processing of video-signals of appropriate CCTV cameras. The specialised products of this type are available on the market and represent the usual solutions e.g. in tunnels and especially important sections of roads, where they detect a stopped vehicle, illegal half turns, driving in wrong direction, and similar. A much more complex system for traffic incident detection is the one on open road sections. Due to economic reasons, the installation of CCTV system is here unacceptable. These systems are based on estimation of the traffic state variables (space mean speed, traffic flow, traffic density, etc.) $[8,9,10]$. Based on the reconstruction of the traffic state variables, using various algorithms of the theory of classification and sample recognition, 
possible incidents are detected. These procedures allow also prediction of incident occurrence.

The application of the procedures of traffic state variables estimation is based on the macroscopic traffic flow models [11]. The basic problem here is the selection of the appropriate model. It is necessary to assess the complexity of the model and its real possibilities for such an application. Recently, several approaches have been studied and they are more or less based on various applications of the second order traffic flow model $[10,12]$. The next step is the application of appropriate incident detection algorithms. In this paper the classification of various approaches is used by using the results of general theory of process faults detection $[13,14]$. There is, namely, great similarity of traffic incident detection and the appropriate well-defined area of process faults detection in the classical theory of automatic control. The latest research in the field of automatic incident detection is directed to the usage of complex systems that use various sources of information and processing procedures. These solutions lead to the proposal of using the decision support system (DSS), [15].

The paper provides the description of the main elements of the incident management system. The second chapter describes the generalised model of incident management. The main phases of the management process are described (detection/verification, response, clearance, recovery) and general classification of detection/verification methods is presented. The third chapter focuses on the mathematical model of estimating the traffic state variables. For this purpose the appropriate development of the discrete mathematical model of the traffic flow has been presented, as well as the structure of estimator based on the application of the Extended Kalman Filter. An overview of the theory of automatic detection of traffic incidents on open road sections is provided in the fourth chapter. The main algorithm groups that are applied today for these purposes are briefly described. In the end a description of the incident management decision support system as a possible promising future solution is given. An analysis of several factors is made, which in practice significantly affect the quality of work of the incident detection system. The concluding part gives the basic results of the work and the guidelines for future research.

\section{INCIDENT MANAGEMENT PROCESS MODEL}

There are several different events that influence the normal or desired traffic flow in road network. In [5] the following events are identified which may lead to temporary reduction in road network capacity (compared to requirement):

- vehicle-conditioned incidents, ranging from minor vehicle damage to multiple accidents with the injured and fatalities;

- debris / barriers on the road;

- maintenance activities;

- unpredicted congestions;

- any combination thereof.

Another cause is extreme weather conditions, such as heavy rain or storms. Planned events (e.g. sport / cultural activities) or repeating events (e.g. peak congestions in the cities), are less interesting here due to the possibility of planned action.

The incident management process, as shown in Figure 1, is divided into four phases: incident detection and verification, incident response, clearance of the incident and recovery to normal traffic flow. Only the first two phases are described in this paper.

Incident detection may be defined as a process of identifying the space and time coordinates of the in-

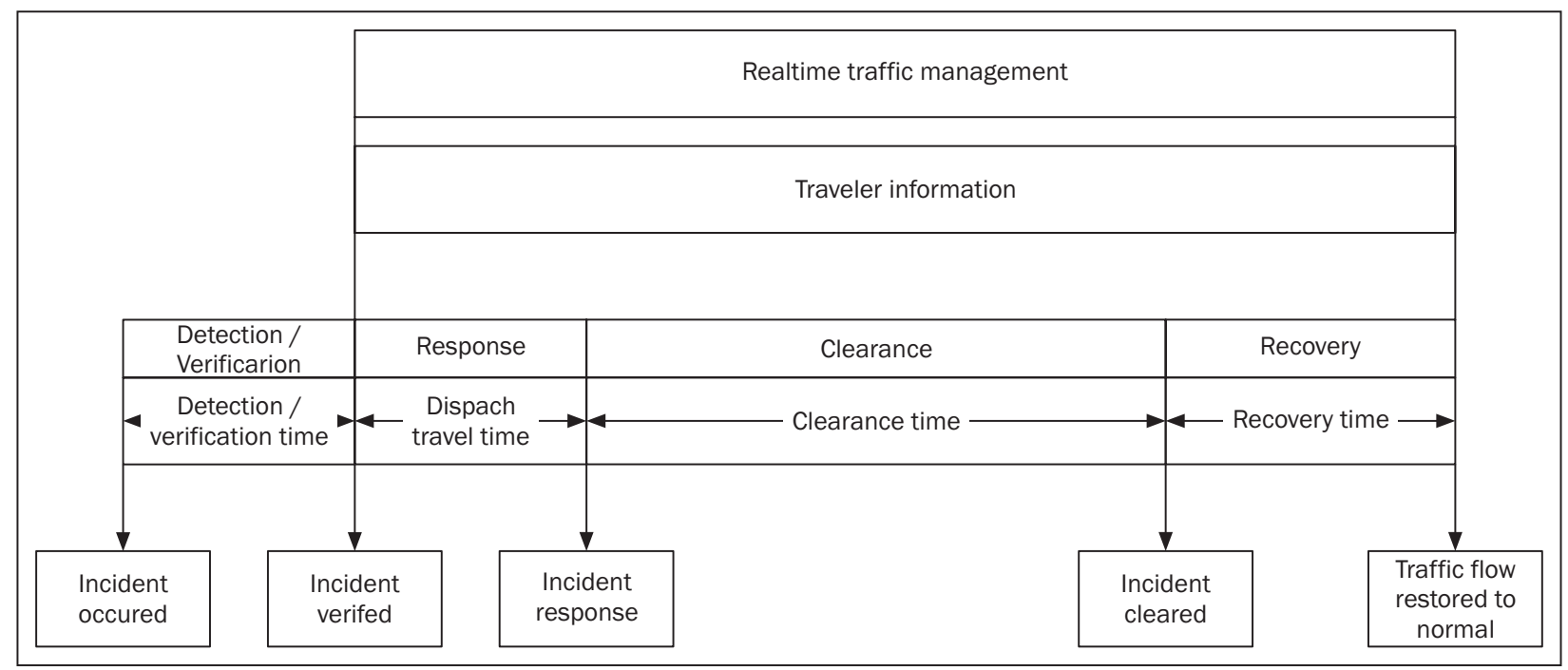

Figure 1 - Phases in incident management 


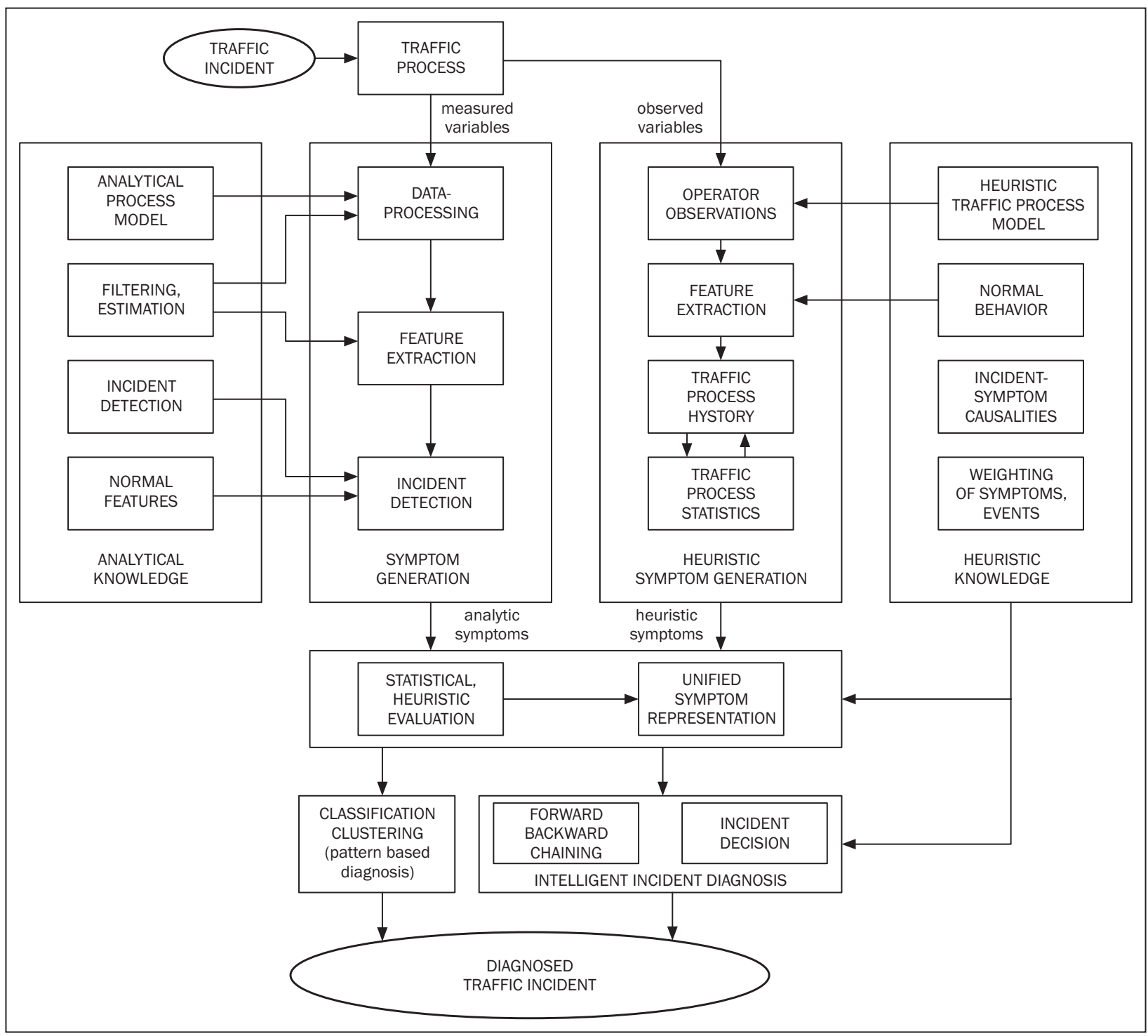

Figure 2 - Incident detection/verification methods and procedures [13, 16]

cident (incident situation) and possible nature of the incident itself. Incident detection methods are realised by private calls (phone, mobile phones), calls from SOS road phones, police report, report of the patrolling services and the operation of the automatic incident detection system. Incident verification means checking, which is used to determine the exact position and nature of the incident. In this way the possibility of responding to false alarms is reduced. Incident verification is carried out by the employees using the image obtained by specialised cameras (CCTV), or based on the comparison of several incoming calls about the incident. Figure 2 shows the basic incident detection/ verification methods and procedures.

The basic classification of detection/verification methods is into heuristic and analytic approach [13, 16]. The heuristic methods are based on qualitative assessment made by the operator (human) about the existing traffic situation and their conclusion whether the concrete traffic situation can be regarded as an in- cident situation. Analytic knowledge about the process is used to generate measurable, analytic information. Therefore, based on the measured traffic flow variables, the data are adequately processed. As result of this processing certain characteristic values are generated. The most significant values can be obtained by:

a) checking whether certain measurable traffic flow variables exceed the pre-defined values (limits),

b) analysing the measurable traffic flow variables by using advanced methods of signal analysis such as correlation function, frequency spectrum, autoregressive moving average process (ARMA), and similar,

c) analyses using mathematical models of the process which includes identification of the road parameters, estimation of the traffic state variables, etc.

In this way, special indicators (coefficients) can be deduced from these characteristic values, i.e. special filtered and transformed residuals (deviations from the 


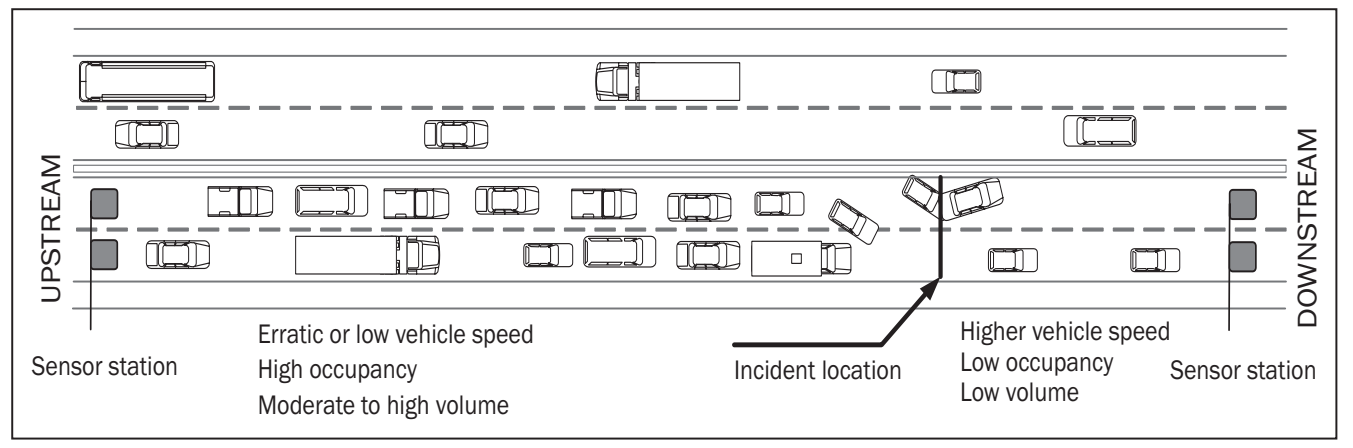

Figure 3 - Incident detection principle on open road sections (freeway)

normal condition). This analysis uses different methods of Traffic Flow Change Detection and Traffic State Classification Methods.

For this, special importance is on the use of adequate sensor technologies. With advance in technology and improvement of hardware new incident detection and verification possibilities are opened up which result in rapid shortening of the time and increase in reliability. Although inductive loops are the most used and very reliable technology for vehicle detection, other technologies are becoming increasingly acceptable as a substitute or addition to inductive loops, especially in cases when the setting of new or replacement of the existing inductive loops is difficult to perform or economically unjustified. The selection of adequate technologies is of special interest in defining the system in road telematics. In this sense, the selection based on multi-criteria decision-making is of special interest [17, 18, 19].

The detection time is the most important parameter in the incident management process. For maximally efficient incident management the incident detection time has to be maximally shortened. Delay in incident detection usually results in queues and traffic congestion, and often cause secondary incidents which very often multiply exceed the incident that caused them.

\section{MATHEMATICAL MODEL OF ESTIMATING TRAFFIC FLOW VARIABLES}

In the introduction of this paper it was mentioned that the most demanding part in incident management is the detection procedure on open road sections (freeway). Since the application by using CCTV cameras on open road sections is still economically unacceptable, different detection methods are used that are based on measuring the variables of the traffic flows. During the incident, the normal traffic flow is disturbed, and this is reflected in the respective traffic flow variables. A simplified scenario of detection is presented in Figure 3. It gives visual presentation of a typical traffic incident situation, traffic pattern and respective sensor installations.
The characteristics of individual traffic flow features during an incident on an open road section can be described in detail by a traffic flow in four adjacent segments, as presented in Figure 4. The flow in segment A, far upstream from the incident, operates at normal speeds with normal density. The flow in segment B, which is immediately in front of the incident location is characterised by vehicle standstill. This segment features the phenomenon of upstream propagation of the shock wave. The speeds are generally low and there is high density of vehicles. The flow in segment $\mathrm{C}$, which is immediately downstream of the incident is characterised by lower traffic density than normal and adequate traffic speed is generally higher than normal. The flow in segment $D$, which is sufficiently far downstream from the incident, has normal density and speed, the same as in segment $A$.

\subsection{Discrete mathematical model of traffic flow}

The traffic variables estimation is based on the familiarity with the macroscopic mathematical traffic flow model. The basic equation of the macroscopic mathematical traffic flow model is the equation of conservation in the following form:

$\frac{\partial \rho(x, t)}{\partial t}+\frac{\partial q(x, t)}{\partial x}=r(x, t)-s(x, t)$

where:

$$
\begin{aligned}
& \rho \text { - traffic density (veh./km/lane), } \\
& q \text { - traffic flow (veh./h), } \\
& r \text { - on-ramp inflow (veh./h), } \\
& s \text { - off-ramp outflow (veh./h), } \\
& t \text { - time coordinate, } \\
& x \text { - location coordinate. }
\end{aligned}
$$

For computer model requirement, the upper partial differential equation is space/time discretized and the set of difference equations is produced. Therefore, the test section is defined by the model presented in Figure 5.

The basic discrete model of individual segment (i) is given in the form:

$\rho_{i}[k+1]=\rho_{i}[k]+\frac{T}{L_{i}}\left(q_{i-1}[k]-q_{i}[k]+r_{i}[k]-s_{i}[k]\right)$ 


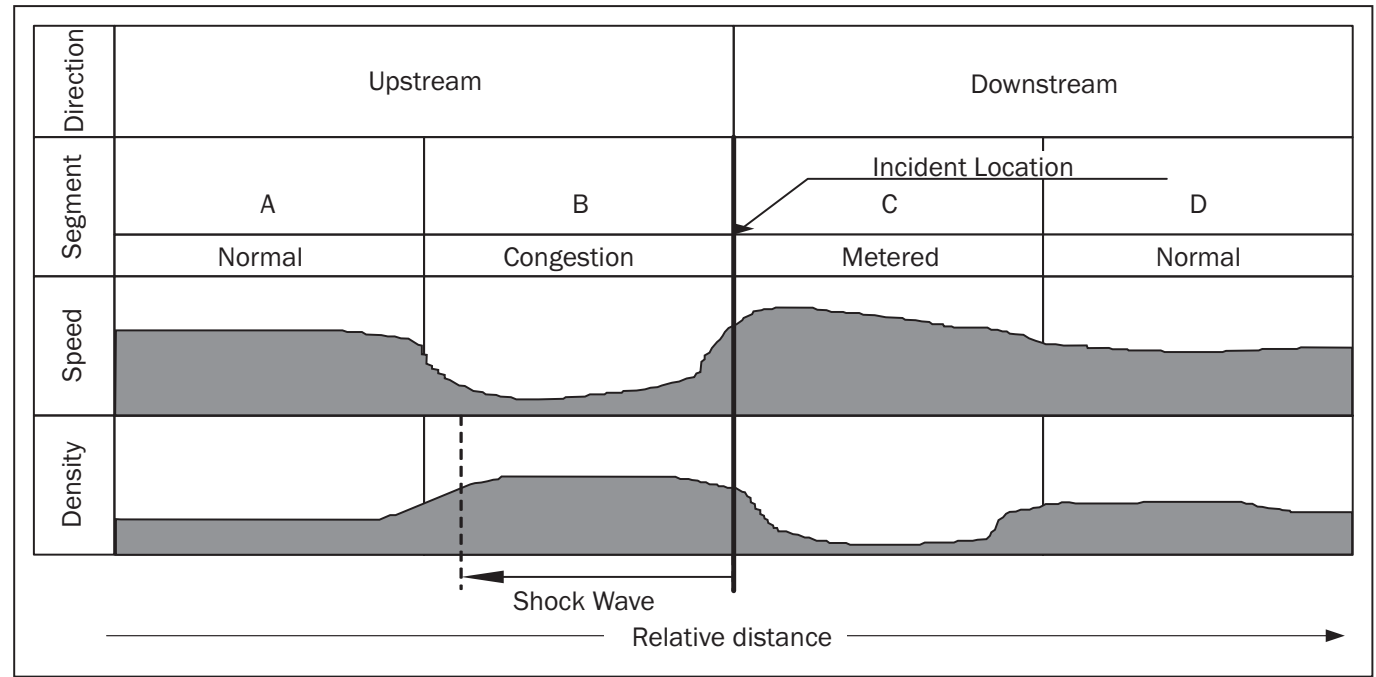

Figure 4 - Traffic flow characteristics during incident [2]

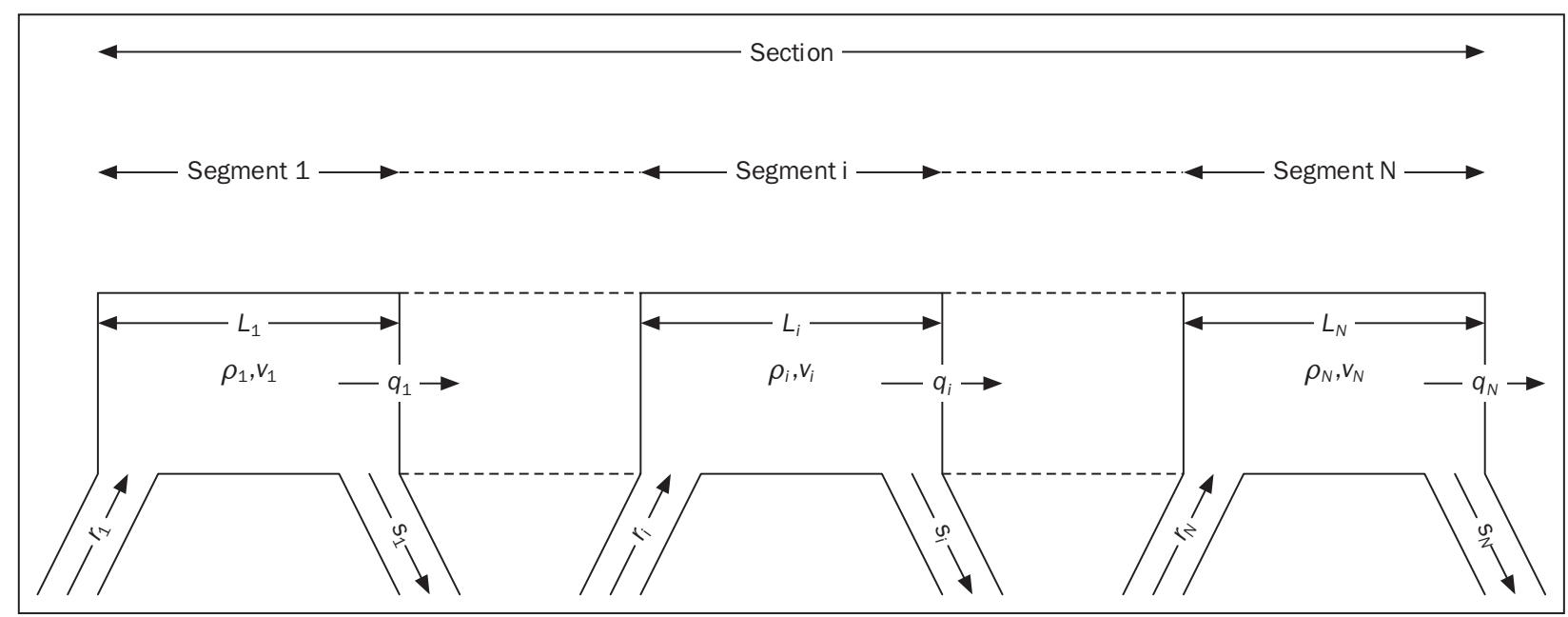

Figure 5 - Physical discretisation of the test section

Where $k$ is a time discretisation step. In the procedure of discretisation of partial differential equations special attention should be paid to the size of the space/time step of discretisation. One conservative approach defines the criterion of the size of the space/ time step of discretisation in the form:

$\frac{L_{i}}{T}>v_{f}$

where:

$L_{i}$ - space discretisation value,

$T$ - time discretisation value,

$v_{f}$ - free flow speed.

The above state may be simply explained by the fact that vehicles that move at a speed of the free flow must not pass the entire segment during one time interval.

It is especially favourable to build into the basic model of the equation of conservation (2) the multilane model. In this way partial reduction of road capacity by losing one or several lanes can be modelled. In this case the model of the equations of conservation acquires the form:
$\rho_{i}[k+1]=\rho_{i}[k]+\frac{T}{L_{i} \lambda_{i}}\left(q_{i-1}[k]-q_{i}[k]+r_{i}[k]-s_{i}[k]\right)$

Parameter $\lambda$ describes the multi-lane impact on the road traffic flow, which is dependent on the reduction coefficient (influence of several traffic lanes on the throughput capacity) $[16,20]$. The values of coefficient $\lambda$ are presented in Table 1.

Table 1 - Impact of several road lanes on traffic flow

\begin{tabular}{||c||c|c|c|c||}
\hline $\begin{array}{c}\text { Number of ac- } \\
\text { tive traffic lanes }\end{array}$ & 1 & 2 & 3 & 4 \\
\hline \hline$\lambda$ & 1.00 & 1.80 & $\begin{array}{c}2.25- \\
-2.34\end{array}$ & $\begin{array}{c}2.40- \\
-2.60\end{array}$ \\
\hline
\end{tabular}

In order to define the second order macroscopic stochastic mathematical model, the equation of conservation is supplemented by the following equations:

- stationary speed equation

$$
v\left(\rho_{i}\right)=v_{f} \exp \left(-\frac{1}{a}\left(\frac{\rho_{i}}{\rho_{c r i}}\right)^{a}\right)
$$


- dynamic speed equation

$$
\begin{aligned}
& v_{i}[k+1]=v_{i}[k]+ \\
& \quad+\frac{T}{\tau}\left(V\left(\rho_{i}[k]\right)-v_{i}[k]\right)+ \\
& \quad+\frac{T}{L_{i}} v_{i}[k]\left(v_{i-1}[k]-v_{i}[k]\right)- \\
& \quad-\frac{\nu T}{\tau L_{i}} \frac{\rho_{i+1}[k]-\rho_{i}[k]}{\rho_{i}[k]+\kappa}+\xi_{i}^{v}[k]
\end{aligned}
$$

- traffic flow equation

$$
q_{i}[k]=\rho_{i}[k] \cdot v_{i}[k] \cdot \lambda_{i}+\xi_{i}^{q}
$$

The above system of equations is described by the well-known Payne model [21]. The dynamic speed equation describes the actual drivers' behaviour taking into consideration the mean traffic flow speed and the traffic state in segment after and in front of the current segment. Term (a) is convection part, term (b) is relaxation part, and term (c) defines the anticipation drivers' behaviour. Parameters $\tau, \nu, \kappa$ describe the local traffic characteristics of individual segment, and they are obtained in the procedure of dynamic identification of traffic characteristics of the road section [16, 22]. A special problem lies in determining the statistical characteristics of additive noise of model $\xi_{i}^{V}$ (standard deviation). One of the possible methods is to use the approach such as Singer manoeuvre model and its derivatives [23, 24].

\subsection{Integral mathematical traffic flow model in state space}

In the discrete mathematical model of traffic flow $(4,5,6,7)$ the state variables are the traffic densities $\rho i$, space mean speeds $v_{i}$, and traffic flow $q_{i}$, where $i=1, \ldots, N$. The external inputs into the system are boundary conditions of the systems $q_{0}, v_{0}$ and $\rho_{N+1}$. In order to model the traffic flow on a road section this flow is usually described as Brownian dynamic system, that is:

$s[k+1]=s[k]+n[k]$

where:

$s=\left[\begin{array}{lll}q_{0} & v_{0} & \rho_{N+1}\end{array}\right]^{\top}$

is the vector of exogenous inputs, and $n[k]$ is a sequence of Gaussian white noise, of zero mean value and standard deviation depending on the characteristics of the traffic flow of the concrete segment.

The integral model of the traffic flow for the road section (freeway) can be expressed in the form:

$\boldsymbol{x}[k+1]=\boldsymbol{f}(\boldsymbol{x}[k])+\boldsymbol{\gamma}[k]$

where:

$\mathbf{x}=\left[\begin{array}{llllll}\rho_{1} & v_{1} & \ldots & \rho_{N} & v_{N} & s^{T}\end{array}\right]^{T}$

is vector which defines the traffic state variables, and $\mathrm{y}[\mathrm{k}]$ is a sequence of the Gaussian white noise, of the zero mean value, and standard deviation depending on the inaccuracy of the mathematical model.
The output equation can be presented in the form: $y[k]=g(x[k])+\zeta[k]$

where function $g(x)$ describes the used measuring system and measurement algorithm, and $\zeta[\mathrm{k}]$ is a sequence of the Gaussian white noise, of the zero mean value, and standard deviation depending on the accuracy of the measuring system. Usually it is:

$y[k]=\left[q_{0}[k] \quad v_{0}[k] q_{N}[k] \quad v_{N}[k]\right]^{T}+\zeta[k]$

The measurement procedure depends on the used measuring system. The optimisation procedure in selecting the measuring system is described in [17].

\subsection{Traffic state variables estimator}

By using the model of estimation error in the form of the covariance matrix:

$P[k]=E\left\{(x[k]-\hat{x}[k])(x[k]-\hat{x}[k])^{T}\right\}$

where $\hat{x}[k]$ is the optimal state estimate of state $x[k]$, the goal is to realise the optimal estimator in the sense of minimising the upper covariance matrix. One of the approaches is the well-known Extended Kalman Filter $[25,26]$. Its standard approach has the following form:

$\hat{x}[k+1]=f(\hat{x}[k])+K_{f}[k](y[k]-g(\hat{x}[k]))$

where $K_{f}$ is Kalman filter gain matrix, which is calculated by using the Riccati matrix equation in the discrete form:

$$
\begin{aligned}
& K_{f}[k+1]=\left(F[k] P[k] G[k]^{T}+M[k]\right) \\
& \left(F[k] P[k] G[k]^{T}+R[k]\right)^{-1}
\end{aligned}
$$

where the estimation covariance matrix is calculated recursively in the form:

$$
\begin{aligned}
& P[k+1]=\left(F[k]-K_{f}[k] G[k]\right) P[k] F[k]^{T}+ \\
& +Q[k]-K_{f}[k] M[k]^{T}
\end{aligned}
$$

In the above equations certain terms are:

$$
\begin{aligned}
& F[k]=\left\langle\frac{\partial t}{\partial x}\right\rangle_{x=\hat{x}[k]} \\
& G[k]=\left\langle\frac{\partial g}{\partial x}\right\rangle_{x=\hat{x}[k]}
\end{aligned}
$$

Jacobian matrices which describe the linearised system around estimated state, and matrices Q, R and $M$ adequate covariance matrices of excitation noise, measurement and cross-covariance of excitation and measurement. There is the possibility of implementing different approaches in determining their values $[23,24]$. In using the above algorithm (in one of different applicable versions) the real-time estimate of traffic state variables on the selected road segment is achieved. The selected structure of the model facilitates various possibilities of simulating the incident events (blocking traffic in one or several lanes, complete traffic standstill, traffic congestion on road section, etc.). In order to model the influence of merging vehicles on the inflow ramp, the above model can be extended by adequate members of influence in the dynamic speed equation $[27,28,29]$. 
By using the presented estimate procedure, based on the traffic measurement on a limited number of points of a certain section, it is possible to reconstruct the traffic signature per single segment. These data are the starting element for the usage of the algorithms of automatic traffic incidents detection.

\section{AUTOMATIC DETECTION OF TRAFFIC INCIDENTS ON OPEN ROAD SECTIONS}

In the introduction to this paper it was said that the implementation of CCTV cameras on open road sections (freeway) is still economically unacceptable. For the incident detection requirements various methods based on the estimate of traffic state variables are used. Based on the good estimate of traffic state variables the detection of possible traffic anomalies is carried out. This area generally belongs to the part of the general classification theory.

As the measure of the quality of success of a certain algorithm the following indicators are used [30, 31].

a) DR - Detection Rate is the ratio of the number of detected incidents and the total number of actual incidents,

b) FAR - False Alarm Rate is the ratio of the number of "false" detected incidents and the total number of detection algorithm decisions,

c) TTD - Time to Detection is the time interval from the moment of incident to the moment when the incident has been detected, and it does not include the time necessary for incident verification.

The relation of the detection rate (DR) and false alarm rate (FAR) is not independent and it behaves qualitatively as presented in Figure 6 . This figure shows the optimal area of parameters DR and FR. Insisting on the increase in the detection rate above these values leads to unacceptable growth in false alarm rates (the "price" of increasing the detection rate is connected with the significant rise in "false" alarms).

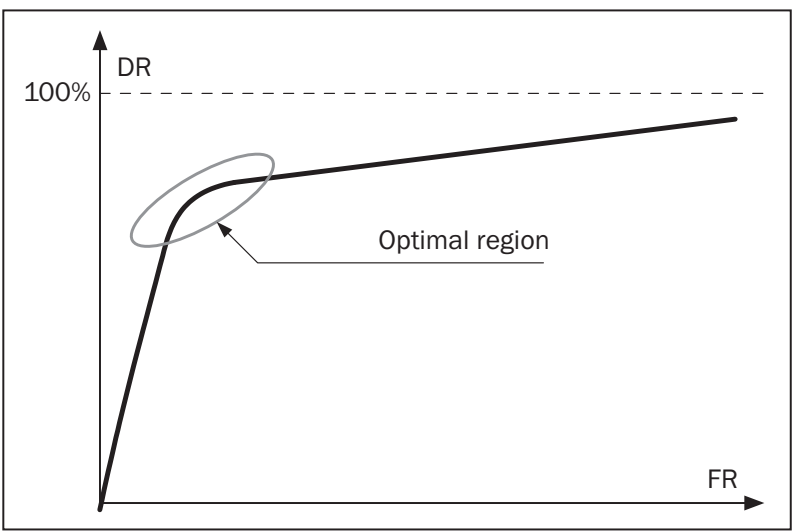

Figure 6 - Theoretical model of DR and FR relation
In past research and implementation, the algorithms of automatic incident detection in traffic could be divided into the following approaches:

1) Statistical theory;

2) Pattern based algorithms;

3) Catastrophe theory;

4) Artificial intelligence.

\section{Statistical theory}

Such approach was developed as early as in the 1970s and it is based on the statistical deduction of the relation of measurement and estimated state of "normal" traffic. The especially appropriate method is based on the Bayesian algorithms of calculating the probability of incident occurrence in the downstream area [32]. The algorithm calculates the conditional probability that the traffic has "deteriorated" due to an incident.

\section{Pattern based algorithms}

Algorithms based on the pattern theory are usually algorithms in present operative. They operate on the principle of traffic flow occupancy, traffic volume and information on the traffic flow which are usually taken over from the measurement system. By sample identification in the data that are not considered "normal" for a certain road, the potential incident is recognised. The best known representative of this approach in automatic incident detection is the so-called California algorithm, developed in the late 1960s for the usage on the Los Angeles highway [33]. The algorithm is based on three tests that are performed on the data about the passage between two adjacent detectors, and the calculation of "thresholds" with which the results are to be compared. If the planned threshold is exceeded, incident is pronounced.

\section{Catastrophe theory}

The catastrophe theory is a relatively older scientific discipline originated from the theory of sensitivity. It studies the influence of minor changes of single parameters on the total system behaviour. In case of incident detection in traffic these are speed, flow and occupancy of the traffic space. For instance, when speed is significantly reduced, without respective increase in occupancy and flow, this will result in incident announcement. The algorithms based on the catastrophe theory can distinguish between the incident and normal congestion. Congestions are created gradually, whereas incidents cause sudden changes which drastically affect the current flow speed. The representative of algorithms which belongs to this group is the McMaster algorithm [34]. Basically, it uses the model of catastrophe theory to describe the flow - lane occupancy relation. 


\section{Artificial intelligence}

Algorithms based on artificial intelligence use different procedures of Fuzzy logics and Artificial Neural Networks (ANN). In the early 1990s the researchers at the University in California presented the possibility of using artificial neural network for incident detection $[35,36]$. The artificial neural network consists of three layers: input layer which receives the data from the measurement system, hidden layer which processes the data and external layer which generates the signal depending on whether it is an incident or normal traffic flow state. In application of artificial neural network the selection of adequate learning examples is of special importance. The "intelligence" of these methods depends most on this selection. Today the orientation is increasingly towards the structures known as neurofuzzy expert systems.

The recent approaches in incident detection in traffic are based on the usage of several different approaches through the decision support system (DSS) [15]. Usually, such decision support systems are based on the voting principle, with built-in restrictions.

\section{DECISION SUPPORT SYSTEM FOR INCIDENT MANAGEMENT}

The latest research in the field of automatic incident detection in traffic refers to the usage of complex systems that use different sources of information and processing procedures [15, 37]. Such solutions lead to the proposal of using the decision support system. The information flow in one such system is presented in Figure 7. Such systems require significant integration of information from various sources. The past experiences, namely, of implementing the traffic incident detection system show significant correlation of different causes of incident occurrence. In this sense different procedures of information fusion are proposed, with the aim of improved detection (better level of detection, reduction of false alarms, and shortening of time necessary for safer detection).

Apart from the standard parts, a system like this has the following functionalities:

- monitoring and reporting of the services in the field,

- predictive estimate of danger, dangerous spots and law violation,

- real-time monitoring of vehicles and creation of traffic situation picture,

- saving and referencing of all events related to the incident,

- real-time reconstruction of events,

- intelligent contact lists of the crucial participants in incident management,

- generation of automatic messages that are forwarded to different control panels in control cen- tres, different agencies, technical groups or individuals.

In construction of such systems one should pay attention that several factors affect the quality of the operation of the incident detection subsystem. The crucial factor is the currently operative condition of the road (freeway) in relation to its design capacity. The experience shows, namely, that it is very difficult to determine that a traffic incident has occurred on the road, in case when the current traffic is significantly lighter than the highway capacity. This is the consequence of information insufficiency. Besides, the variations in traffic flow have a daily rhythm, with two - three peaks in the hours of the busiest traffic. In this case, these daily and hourly variations in traffic exclude the application of simple threshold algorithms. Such algorithms do not recognise the nature of temporal variation of traffic picture during the day.

The grade of the road, the change in the number of lanes and the existence of approach ramps makes the identification of certain traffic situations difficult, as well as the patterns of single traffic incidents. Similarly, the external factors such as the condition of road surface and meteorological condition will affect the traffic picture regardless of the incident occurrence (for example heavy rain and snow change the picture of the traffic flow).

The performances of simple detection algorithms that use the comparison of measurements on two or more spaced detectors depend significantly on the gap between detector stations. The presence of approach ramps, lane merging and other geometrical road characteristics need to be considered with special attention. Good starting basis for the determination of the positions of detector stations is that the same throughput conditions on the selected measurement segment are valid.

The previous studies have shown that vehicle heterogeneity on the road section significantly affect the performances of the detection algorithm, [31, 37]. Most of the algorithms assume large participation of the vehicles of the same type, which dictate a certain picture of the traffic flow. A disproportionate percentage of big trucks will have the tendency of slowing down the traffic and increase the headway. This may cause such a change in the picture of the traffic flow, that some detection algorithms pronounce this as incident.

All the mentioned elements indicate the need for application of a far more complex structure. Some experiences in the application of the decision support system, as expert systems derivative, indicate the possibility of these artificial intelligence technologies. Such approach allows the installation of knowledge bases and inference engines that have the capacity of high-quality processing of such complex information. 


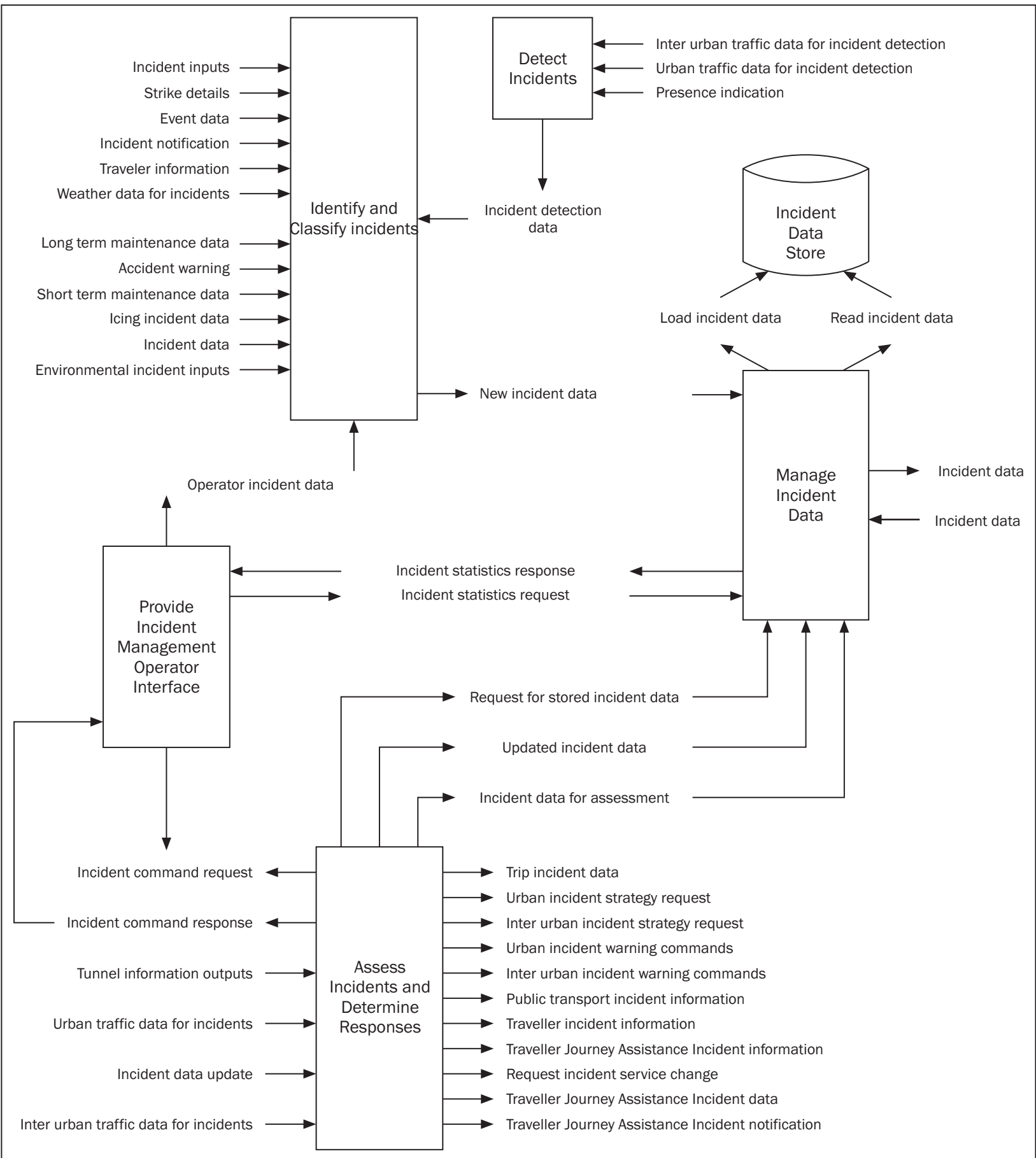

Figure 7 - Information flow model in IMDSS

\section{CONCLUSION}

The objective of this paper is to present the possibilities of achieving maximally effective and efficient development and implementation of the real-time traffic incident management system. It emphasises the special significance on the timely incident detection. The efficient management of available information, data exchange as well as intelligent real-time decision-making can reduce the consequences of traf- fic incidents, especially, prevent secondary incidents. Advanced inventive technologies and the approach based on the intelligent transport system paradigm, significantly improve the system performances. The main performance characteristics taken into consideration are response time and reduction of harmful consequences from incidents. .

The future work should study the possibilities of different realisations of the algorithm for traffic flow variables estimation. Therefore, a promising approach 
is based on the implementation of neuro-fuzzy estimators, which may include also the incident detection algorithms. The authors' opinion is certainly that such systems will lead in the future to technologies based on the today already proven approach to the decision support system i.e. expert systems. Special effort should be directed also to the study of the possibility of predicting the incident. Some past researches have shown that in some situations an incident can be predicted (forecast) with fairly sufficient probability. In that case, the final results referring to the prevention of the incident itself can be of great significance.

\section{Mr. SC. PERO ŠKORPUT}

E-mail: pero.skorput@fpz.hr

Dr. Sc. SADKO MANDŽUKA

E-mail: mandzukas@fpz.hr

Dr. SC. NIKO JELUŠIĆ

E-mail: jelusicn@fpz.hr

Sveučilište u Zagrebu, Fakultet prometnih znanosti

Vukelićeva 4, 10000 Zagreb, Republika Hrvatska

\section{SAŽETAK}

\section{STVARNO-VREMENSKA DETEKCIJA INCIDENATA U CESTOVNOM PROMETU}

U radu se analizira stvarno-vremenska detekcija incidenata u cestovnom prometu. Daje se opći model integralnog sustava za upravljanje incidentima u cestovnom prometu. Prikazane su najznačajnije metode detekcije incidenata. Posebno je obrađen postupak detekcije na otvorenim dionicama autocesta. Definiran je odgovarajući matematički model, kao podloga za realizaciju estimatora varijabli stanja prometnog toka. Kao metoda predložen je prošireni Kalmanov filtar. U završnom dijelu rada dan je primjer za realizaciju sustava potpore odlučivanja u upravljanju incidentnim situacijama (IMDSS - Incident Management Decision Support System).

\section{KLUČNE RIJEČI}

inteligentni transportni sustav, sustav upravljanja incidentima, model prometa u prostoru stanja, teorija estimacije, prošireni Kalmanov filtar, automatska detekcija incidenata, sustav potpore odlučivanju

\section{LITERATURE}

[1] Bošnjak, I., Intelligent Transportation Systems 1, Faculty of Transport and Traffic Sciences, Zagreb, 2006 (in Croatian)

[2] Intelligent Vehicle Highway Systems: The State of the Art, JHK and Associates, New York, NY, March 1993

[3] Hegyi, A., Girimonte, D., Babuska, R., \& De Schutter, B., A comparison of filter configurations for freeway traffic state estimation. In Proceedings of the $9^{\text {th }}$ international IEEE conference on Intelligent Transportation Systems, 2006

[4] Roy, P., Abdulhai, B., GAID: Genetic adaptive incident detection for freeways, TRB $82^{\text {nd }}$ Annu. Meeting, Washington, DC, 2003.
[5] Škorput, P., Real-time incident management system, M.Sc. Thesis, Faculty of Transport and Traffic Sciences, Zagreb, 2009 (in Croatian)

[6] Dudek, C.L., Messer, C.J. and Nuckles, N.B., Incident detection on urban freeways. Transportation Research Record, 495 pp. 12-24., 1994.

[7] Dia, H., Rose, G., Snell, A., "Comparative performance of freeway automated incident detection algorithms," in Proc. Roads 96: Joint 18th ARRB Transp. Res. Conf. and Transit New Zealand Land Transp. Symp., pt. 7, pp. 359-374, 1996

[8] Papageorgiou, M., Blosseville, J.-M., \& Haj-Salem, H., Modelling and real-time control of traffic flow on the southern part of Boulevard Périphérique in Paris, Part I: Modelling. Transportation Research A, 24, 345-359, 1990

[9] Kotsialos, A., Papageorgiou, M., The importance of traffic flow modelling for motorway traffic control, Networks and Spatial Economics, 1, 179-203, 2001

[10] Wang, Y., Papageorgiou, M., \& Messmer, A., Real-time freeway traffic state estimation based on extended KaIman filter: A case study. Transportation Science, 41, 167-181, 2007

[11] Cremer, M., Flow variables: estimation. In: Concise Encyclopedia of Traffic and Transportation Systems. Pergamon Press, 143-148., 1991.

[12] Wang, Y., Papageorgiou, M., Messmer, A., Renaissance-A unified macroscopic model based approach to real-time freeway network traffic surveillance, Transportation Research Part C 14, 190-212, 2006

[13] Isermann, R., Process faults detection based on modelling and estimation methods, A survey, Automatica 20 (4), 387-404, 1984

[14] Willsky, A. S., A survey of design methods for failure detection in dynamic systems, Automatica 12, $601-$ 611, 1976

[15] Mitrovich, S., Valenti, G., Mancini, M., A Decision Support System (DSS) for Traffic Incident Management in Roadway Tunnel Infrastructure, Association for European Transport and contributors, 2006

[16] Mandžuka, S., Application of artificial neural networks in intelligent telematics, TEB Elektronika, Zagreb, 2010 (in Croatian)

[17] Jelušić, N.: The Evaluation of Sensor Technology in Automatic Road Traffic Control System, PhD Thesis, Faculty of Traffic and Transport Sciences University of Zagreb, 2008 (in Croatian)

[18] Jelušić, N., Anžek, M., Ivanković, B., Information Source Quality in Intelligent Transport Systems, Promet-TrafficTransportation, 125-134, 2010

[19] Jelušić, N., Anžek, M., Mandžuka, S., Evaluation of sensor technologies for ITS, Proceedings of $16^{\text {th }}$ ITS World Congress, Stockholm: Ertico, 2009

[20] Legac, I., Roads 1, Public Roads, Faculty of Transport and Traffic Sciences, 2006, (in Croatian)

[21] Payne H.J., Models of freeway traffic and control, Mathematical Models of Public Systems, (G.A. Bekey, ed.), Vol. 1, No. 1, Simulation Council Proceedings Series, pp. 51-61, La Jolia, California, 1971

[22] Papageorgiou M., Dynamic modeling, assignment, and route guidance in traffic networks, Transportation Research B, vol. 24B, no 6, pp. 471-495, 1990 
[23] Li, X.R., Jilkov, V.P., Survey of Maneuvering Target Tracking, Part I: Dynamic Models, IEEE Transactions On Aerospace and Electronic Systems Vol. 39, No. 4, 2003

[24] Mandžuka, S., Ship tracking control: Optimal estimation of navigation parameters, In Proceedings of the $42^{\text {th }}$ International Symposium, ELMAR, Zadar, 2000

[25] Jazwinsky, A. H., Stochastic processes and filtering theory. NewYork: Academic Pres, 1970

[26] Sorenson, H. W., Kalman filtering: Theory and application, IEEE Pres, New York, 1985

[27] Wang, Y., \& Papageorgiou, M., Real-time freeway traffic state estimation based on extended Kalman filter: A general approach. Transportation Research B, 39, 141-167, 2005

[28] Wang, Y., Papageorgiou, M., \& Messmer, A., An adaptive freeway traffic state estimator and its real data testing, Part II: Adaptive capabilities. In Proceedings of IEEE 8th international conference on intelligent transportation systems, 537-542, 2005

[29] Wang, Y., Papageorgiou, M., \& Messmer, A., Real-time freeway traffic state estimation based on extended KaIman filter: A case study. Transportation Science, 41 167-181, 2007

[30] Ritchie, S.G., Cheu, R.L., Simulation of Freeway Incident Detection Using Artificial Neural Networks, Transportation Research Part C: Emerging Technologies. Vol. 1, No. 3. Pergamon Press, 1993.
[31] Al-Deek M., Implementation of Incident Detection Algorithms, UCF Transportation Systems Institute, August 1999.

[32] Levin, M., Krause, G., Incident Detection: A Bayesian Approach. Transportation Research Record 682 (5258), 1978.

[33] Payne, H.J., Tignor, S.C., Freeway Incident Detection Algorithms Based on Decision Trees with States, Transportation Research Record 682 (30-37),1978.

[34] Antoniades, C.N., Stephanedes, Y.J., Single-Station Incident Detection Algorithm (SSID) for Sparsely Instrumented Freeway Sites. Transportation Engineering, 1996.

[35] Stephanedes, Y.J., Liu, X., Artificial Neural Networks for Freeway Incident Detection. Transportation Research Record 1494 (91-97), 1995.

[36] Ritchie, S.G., Cheu, R.L., Simulation of Freeway Incident Detection Using Artificial Neural Networks. Trasportation Research Part C. Volume 1, (313-331). Pergamon Press, New York, 1993.

[37] Zografos K.G., Androutsopoulos K.N., Vasilakis G.M., A real-time decision support system for roadway network incident response logistics, Transportation Research Part C: Emerging Technologies, 10 (1), 2002 